\section{Formulation Development and Evaluation of Mouth Dissolving Tablets of Loratadine}

\author{
Abul Kalam Lutful Kabir ${ }^{1^{*}}$, Shaikh Mukidur Rahman ${ }^{2}$, Md. Arshad \\ Jahan $^{3}$, Abu Shara Shamsur Rouf ${ }^{2}$ \\ Department of Pharmacy, Jagannath University, Dhaka ${ }^{1}$, Bangladesh \\ Department of Pharmaceutical Technology, University of Dhaka ${ }^{2}$, \\ Department of Pharmacy, University of Rajshahi, Rajshahi ${ }^{3}$
}

*Corresponding Author

Abul Kalam Lutful Kabir Lecturer, Department of Pharmacy Jagannath University Bangladesh Contact No.: 01920764100 E-mail: lkabir81@yahoo.com

\begin{abstract}
Difficulty in swallowing (dysphagia) is common among all age groups, especially in elderly and pediatrics. Mouth dissolving tablets constitute an innovative dosage forms that overcome the problems of swallowing and provides a quick onset of action. The purpose of this study was to formulate and evaluate mouth dissolving tablet of loratadine using a special preparation technology (pharmaburst Technology) with a super disintegrating agent (Croscarmellose sodium). Tablets were prepared by direct compression technique. The granules were evaluated for angle of repose, bulk density, tapped density, bulkiness, compressibility index and hausners ratio. The tablets were evaluated for hardness, thickness, uniformity of weight, friability, wetting time, water absorption ratio, disintegration time and drug content. In vitro release studies were performed using USP-II (paddle method) in $900 \mathrm{ml}$ of $\mathrm{pH} 1.2$ at $50 \mathrm{rpm}$. The physical properties of the prepared tablets did not show any significant variations and were found to have good physical integrity. Tablets prepared with pharmaburst B2 and Croscarmellose sodium showed a lesser disintegration time and wetting time of $27 \pm 0.10$ and $38 \pm 0.13$ seconds respectively. The best formulations were subjected to stability studies at $40^{\circ} \mathrm{C} / 75 \% \mathrm{RH}$ for 60 days.
\end{abstract}

Key words: Loratadine, pharmaburst B2, croscarmellose sodium, mouth dissolving tablets, direct compression.

\title{
INTRODUCTION
}

Tablets that disintegrate or dissolve rapidly in the patient's mouth are convenient for young children, the elderly and patients with swallowing difficulties, and in situations where potable liquids are not available. For these formulations, the small volume of saliva is usually sufficient to result in tablet disintegration in the oral cavity. The medication can then be absorbed partially or entirely into the systemic circulation from blood vessels in the sublingual mucosa, or it can be swallowed as a solution to be absorbed from the gastrointestinal tract. The sublingual route usually produces a faster onset of action than orally ingested tablets and the portion absorbed through the sublingual blood vessels bypasses the hepatic first-pass metabolic processes (David et al 2008). Loratadine, a piperidine derivative related to azatadine, is a long-acting, non-sedating antihistamine with no significant antimuscarinic activity. It is used for the symptomatic relief of allergic conditions such as runny nose, itchy or watery eyes, sneezing, and nasal or throat itching and chronic urticaria(Haria M, et al 1994). It is also licensed to alleviate itching due to hives. It does not readily cross the blood brain barrier. Due to a bypass of first-pass metabolism, approximately $40 \%$ of the absorbed loratadine is absorbed via the oral mucosa (Lene NoehrJensen 2006). Hence, an attempt was made for preparation of mouth dissolving tablets of loratadine with an aim of reducing the lag time and providing faster onset of action to relieve the allergic conditions immediately. Mouth dissolving tablets (MDT) are formulated by utilizing several processes, which differ in their methodologies and the MDTs formed vary in various properties susch as, mechanical strength of tablet, taste and mouth feel, swallowability, drug dissolution in saliva, bioavailability and stability. Various processes employed in formulating MDTs include Freeze-Drying or Lyophilization, cotton candy process, molding, spray drying, mass extrusion and compaction (wet granulation, dry granulation, direct compression). This study has been performed by using direct compression process (the simplest and most cost effective tablet manufacturing technique for MDTs) with a patent technology (Pharmaburst Technology). 


\section{MATERIALS AND METHODS}

\section{Experimental material}

Loratidine and pharmaburst B2 were a gift sample from Square Pharmaceuticals Ltd, Bangladesh. Croscarmellose sodium, Strawberry and Aspartame were obtained from Tuhin Chemicals, Dhaka. Avicel Ph 102, Aerosil-200, Purified talc, Magnesium Stearate were purchased from local market, Dhaka. Solvents and reagents: Hydrochloric acid (Merck, Germany); Methanol and acetonitrile (Merck, Germany); All other ingredients used were of analytical grade.

Equipments: Single punch tablet press (Shanghai-Tianhe Pharmaceutical Machinery Company); HM Semi Auto Blister Pack Machine( China), UV Spectrophometer (Shimadzu, Japan); Digital pH meter (Hach Company, USA); Electronic Hardness tester (Ereweka,Germany); Tablet Dissolution Tester (Electrolab, India); Sartorius Electronic Balance.

Preparation of dissolution medium: For the preparation of simulated gastric medium $(0.1 \mathrm{~N} \mathrm{HCl}, \mathrm{pH}$ 1.3) $11.4 \mathrm{ml}$ of Hydrochloric acid (32\% w/v) was diluted with sufficient water to produce $1000 \mathrm{ml}$.

\section{Preparation of tablets}

The tablets were prepared by simple blending of active ingredient with polymer, filler, binder, lubricant and flow promoter followed by direct compression (Table-1). 50 tablets were prepared for each proposed formulation. Properly weighed Croscarmellose Sodium, Pharmaburst B2 Ph. Grade, Avicel Ph 102, Aspartame, Strawberry, Aerosil-200, Purified talc, Magnesium Stearate and the active ingredient were sieved through sieve no. 40 and then taken in a photo film container and blended in a laboratory designed small drum blender machine for 30 minutes to ensure thorough mixing and phase homogenization. This mixed blend was compressed into tablet weighing $195 \mathrm{mg}$ using $10.00 \times 7.00 \mathrm{~mm}$ oval shaped, flat bevel Single punch tablet press (Shanghai-Tianhe Pharmaceutical Machinery Company) to a hardness of 4-7 Kp. The compressed tablets were dedusted and evaluated for various tablet properties.

Table 1. Formulation of Mouth dissolving tablets of Loratadine in $\mathrm{mg}$.

\begin{tabular}{lcccc}
\hline Formulation Ingredients & F-1 & F-2 & F-3 & F-4 \\
\hline Loratadine & 10 & 10 & 10 & 10 \\
Croscarmellose Sodium & - & - & - & 3 \\
PharmaburstB2Ph.Grade & 130 & 140 & 150 & 150 \\
Avicel Ph 102 & 35 & 25 & 15 & 12 \\
Aspartame & 3 & 3 & 3 & 3 \\
Strawberry essence & 4 & 4 & 4 & 4 \\
Aerosil-200 & 2 & 2 & 2 & 2 \\
Purified talc & 6 & 6 & 6 & 6 \\
Magnesium Stearate & 5 & 5 & 5 & 5 \\
Total weight & 195 & 195 & 195 & 195 \\
\hline
\end{tabular}

\section{Evaluation of Granules}

Angle of repose

Angle of repose $(\theta)$ was determined using fixed funnel method. The height of the funnel was adjusted in such a way that the tip of the funnel just touched the apex of the heap of the granules. The granules were allowed to flow through the funnel freely onto the surface ${ }^{7}$. The diameter of the granular cone was measured and angle of repose was calculated using the following equation.

$\theta=\tan -1(\mathrm{~h} / \mathrm{r})$, Where $\mathrm{h}$ and $\mathrm{r}$ are the height and radius of the cone.

\section{Bulk Density}

Bulk density is a characteristic of a powder rather than individual particles and is given by the mass, M, of powder occupying a known volume, V, according to the relationship (Aulton 1998).

Bulk density $=$ Mass of powder (M)

It is expressed by $\mathrm{gm} / \mathrm{cc}$. 


\section{Tapped Density}

Tapped density is the ratio between mass of granules and volume of the granules after tapping (USP-30 NF 2007). It is expressed by gm/cc.

Tapped Density $=$ Weight of granules $/$ Tapped volume

\section{Bulkiness}

Reciprocal of bulk density is known as bulkiness (Patrick 2006). It is expressed by cc/gm.

Bulkiness $=1 /$ Bulk density

\section{Compressibility index and hausner ratio}

The compressibility index and the closely related hausner ratio have become the simple, fast and popular methods of predicting powder flow characteristics. The compressibility index and hausner ratio were determined by measuring both the bulk density and tapped density of granules.

Compressibility Index $=100^{*}$ (1-Bulk density/Tapped density)

Hausner ratio $=$ Tapped density $/$ Bulk density

\section{Evaluation of tablets \\ Hardness}

The strength of tablet is expressed as tensile strength $(\mathrm{kp})$. The tablet crushing load, which is the force required to break a tablet by compression (Rudnic 1990). It was measured using a tablet hardness tester (Ereweka, Germany).

\section{Thickness}

Checked the thickness of 05 tablets by a thickness tester (Ereweka, Germany) calculated and recorded the average of thickness of 10 tablets.

\section{Weight variation}

Twenty tablets were randomly selected and individually weighed (Sartorius Electronic Balance). The average weight of the selected tablets was calculated (USP-30 NF 2007).

\section{Friability}

Friability test is performed to assess the effect of friction and shocks, which may often cause tablet to chip, cap or break. Roche friabilator was used for the Purpose. Preweighed sample of ten tablets were placed in the friabilator, which was then operated for 100 revolutions. After 100 revolutions the tablets were dusted and reweighed. Calculate the percentage loss in weight as follows.

Calculation:

$$
\% \text { of loss }=\frac{(A-B)}{A} \times 100 \%
$$

Where, $A=$ Initial weight of 20 tablets, $B=$ Final weight of 20 tablets.

Compressed tablets should not loose more than $1 \%$ of their weigh (USP-30 NF 2007).

\section{Disintegration Time}

The test was carried out on six tablets using distilled water at $370 \mathrm{C}+20 \mathrm{C}$ was used as disintegration media and the time in second taken for complete disintegration of the tablet with no palable mass remaining in the apparatus was measured in seconds (Mukesh, 2009).

\section{Wetting time}

Five circular tissue paper of $10 \mathrm{~cm}$ diameter were placed in a petridish with a $10 \mathrm{~cm}$ diameter. $10 \mathrm{ml}$ of simulated saliva $\mathrm{pH}$ (phosphate buffer $\mathrm{pH}$ 6.8) was poured into the tissue paper placed in the petridish. A tablet was placed carefully on the surface of the tissue paper. The time required for the solution to reach upper surface of the tablet was noted as the wetting time (Mukesh, 2009).

\section{Water absorption ratio}

The weight of the tablet before keeping in the petridish was noted $(\mathrm{Wb})$. Fully wetted tablet from the petridish was taken and reweighed $(\mathrm{Wa})$. The water absorption ratio $\mathrm{R}$ can be determined according to the following formula.

$\mathrm{R}=(\mathrm{Wa}-\mathrm{Wb}) / \mathrm{Wa} \times 100$ 


\section{Estimation of drug content}

Transfer 10 Tablets into a $250 \mathrm{ml}$ volumetric flask; add $100 \mathrm{ml}$ of $0.05 \mathrm{~N}$ Hydrochloric acid and shake for 40 minutes or until the Tablets are completely disintegrated. Add $75 \mathrm{ml}$ of a mixture of methanol and acetonitrile (1:1), and mix. Add $20 \mathrm{ml}$ of $0.6 \mathrm{M}$ Dibasic potassium phosphate, and mix for 5 minutes. Dilute with a mixture of methanol and acetonitrile (1:1) to volume, and mix. From this suitable dilution was prepared and the solution was analyzed at $280 \mathrm{~nm}$ using UV Spectrophometer (Shimadzu, Japan) using $0.1 \mathrm{~N}$ Hydrochloric acid solution as a blank.

\section{In-Vitro Release Profile of Formulated Tablets}

The dissolution of mouth dissolving tablets of loratadine was carried out in USP-II (paddle type) dissolution apparatus. The dissolution medium was $900 \mathrm{ml}$ of gastric simulated fluid (without enzyme) $\mathrm{pH} 1.2$ maintained at $37^{\circ} \mathrm{C}$. The paddle was rotated at $50 \mathrm{rpm}$ for $20 \mathrm{~min}$. The sample of $10 \mathrm{ml}$ was withdrawn after every $2 \mathrm{~min}$. and its absorbance was measured at $280 \mathrm{~nm}$.

\section{Stability studies}

Tablets of formulation (F-4) were blistered in HM Semi Auto Blister Pack Machine (China) for accelerated stability study. Blisters were kept in satability chamber at $40^{\circ} \mathrm{C} / 75 \% \mathrm{RH}$ for 60 days. At 30 and 60 days, the tablets were examined for physical changes, properties, drug content and in vitro release studies (Swamy 2008). (Tables 5, 6)

\section{RESULTS AND DISCUSSION}

In the present study, mouth dissolving tablets of loratadine were prepared by using pharmaburst B2 and croscarmellose sodium as superdisintegrants. These four formulations were prepared by direct compression technique. The formulated granules were evaluated and the results are shown in the table 2. The angle of repose was in the range of $16.25 \pm 0.057$ to $17.88 \pm 0.072$ which was less than 25 indicating good flow property. The bulk density and tapped density was in the range of $0.3250 \pm 0.0135$ to $0.3398 \pm 0.0198 \mathrm{gm} / \mathrm{cc}$ and $0.3802 \pm 0.0151$ to $0.3902 \pm 0.0219 \mathrm{gm} / \mathrm{cc}$. The bulkiness was in the range of $2.9429 \pm 0.1713$ to $3.0769 \pm 0.1275 \mathrm{cc} / \mathrm{gm}$. The compressibility index and Hausner ratio were in the range of $12.9241 \pm 0.8370$ to $15.0136 \pm 1.6498 \%$ and $1.1485 \pm 0.0110$ to $1.1771 \pm 0.0227$ indicating good flow property.

Table 2. Evaluation of prepared granules of Loratadine

\begin{tabular}{lcccccc}
\hline $\begin{array}{l}\text { Formulat } \\
\text { ion Code }\end{array}$ & $\begin{array}{c}\text { Angle of } \\
\text { repose }(\boldsymbol{\theta})\end{array}$ & $\begin{array}{c}\text { Bulk } \\
\text { density } \\
(\mathbf{g m} / \mathbf{c c})\end{array}$ & $\begin{array}{l}\text { Tapped } \\
\text { density } \\
\mathbf{( g m / c c )}\end{array}$ & $\begin{array}{l}\text { Bulkiness } \\
\text { (cc/gm) }\end{array}$ & $\begin{array}{l}\text { Compressibi } \\
\text { lity } \\
\text { index }\end{array}$ & $\begin{array}{l}\text { Hausner } \\
\text { ratio }\end{array}$ \\
\hline F-1 & $17.88 \pm 0.072$ & $0.325 \pm 0.013$ & $0.380 \pm 0.015$ & $3.076 \pm 0.127$ & $14.521 \pm 0.775$ & $1.170 \pm 0.010$ \\
F-2 & $17.59 \pm 0.051$ & $0.328 \pm 0.018$ & $0.385 \pm 0.019$ & $3.048 \pm 0.167$ & $15.013 \pm 1.649$ & $1.177 \pm 0.022$ \\
$F-3$ & $17.03 \pm 0.049$ & $0.330 \pm 0.012$ & $0.387 \pm 0.017$ & $3.028 \pm 0.117$ & $14.422 \pm 1.609$ & $1.168 \pm 0.022$ \\
F-4 & $16.25 \pm 0.057$ & $0.339 \pm 0.019$ & $0.390 \pm 0.021$ & $2.942 \pm 0.171$ & $12.924 \pm 0.837$ & 1.14850 .011 \\
\hline
\end{tabular}

The compressed tablets were evaluated for physical properties and the results are tabulated in table 3. The hardness was in the range of $4.49 \pm 0.17$ to $5.48 \pm 0.32 \mathrm{Kp}$. Uniformity of weight was found to be in the range of $196.72 \pm 0.69 \mathrm{mg}$ to $199.48 \pm 0.58 \mathrm{mg}$. The friability of all the formulation was within $1 \%$ which was in the range of nil to $0.06 \%$. The wetting time for all the formulated tables was in the range of $38 \pm 0.13$ to $105 \pm 0.43 \mathrm{sec}$. The water absorption ratio was found to be in the range of $44.80 \pm 0.84$ to $47.87 \pm 0.52 \%$. The disintegration time of all the formulated tablets between $27 \pm 0.10$ to $48 \pm 0.19 \mathrm{sec}$. The drug content was in the range of $99.8 \pm 0.29$ to $102.60 \pm 0.42 \%$. F-2, F3 and F-4 formulations were selected for the In vitro release studies. 
Table3. Evaluation of Loratadine mouth dissolving tablets

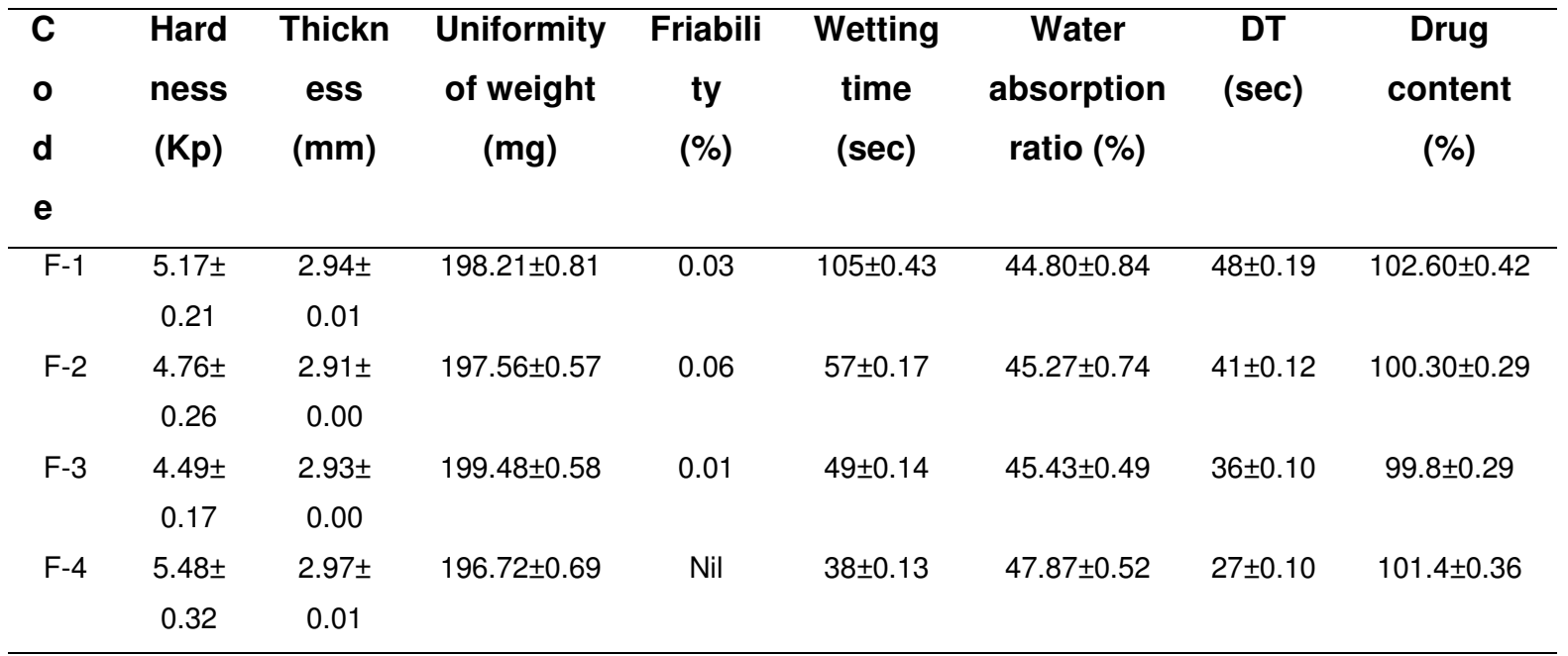

Table 4. In vitro dissolution profile of formulation F-1 to F-4 and the conventional tablet

\begin{tabular}{cccccc}
\hline \multirow{2}{*}{$\begin{array}{c}\text { Time } \\
(\mathbf{m i n})\end{array}$} & F-1 & F-2 & F-3 & F-4 & $\begin{array}{c}\text { Conventional } \\
\text { Tablet }\end{array}$ \\
\cline { 2 - 5 } & & & & & 16.56 \\
4 & 71.43 & 77.65 & 85.05 & 94.49 & 28.85 \\
6 & 79.78 & 86.95 & 88.21 & 98.35 & 46.94 \\
8 & 87.05 & 90.83 & 91.96 & 98.62 & 52.48 \\
10 & 88.90 & 91.06 & 92.56 & 98.97 & 59.36 \\
\hline
\end{tabular}

Table 5. Result of evaluation for hardness, friability and disintegration time in stability studies of mouth dissolving tablet of loratadine(F-4)

\begin{tabular}{cccc}
\hline Time(days) & Hardness(kp) & Friability (\%) & Disintegration time(sec) \\
30 & $5.49 \pm 0.3196$ & $0.02 \pm 0.0012$ & $31.0 \pm 0.11$ \\
60 & $5.46 \pm .3178$ & $.04 \pm 0.0023$ & $30 \pm 0.10$ \\
\hline
\end{tabular}

Table 6. Result of evaluation for hardness, friability and disintegration time in stability studies of mouth dissolving tablet of Loratadine(F-4)

\begin{tabular}{cccccc}
\hline $\begin{array}{c}\text { Time } \\
\text { (days) }\end{array}$ & 02min & 04 $\mathbf{~ i n ~}$ & 06 $\mathbf{~ m i n}$ & 08min & 10 min \\
30 & $94.85 \pm 0.334$ & $98.30 \pm 0.398$ & $98.55 \pm 0.347$ & $98.99 \pm 0.287$ & $99.03 \pm 0.349$ \\
60 & $95.17 \pm 0.276$ & $98.32 \pm 0.285$ & $98.63 \pm 0.399$ & $98.96 \pm 0.348$ & $98.99 \pm 0.287$ \\
\hline
\end{tabular}

The In vitro release study for the formulations F-2, F-3 and F-4 were shown in the figure 2. Over all the MDT formulations of loratadine showed an average of 89.01 to $99.13 \%$ drug release range at the end of $10 \mathrm{~min}$ and it was also observed that F-4 took shortest time to release the maximum amount of drug whereas the other formulation took more than $10 \mathrm{~min}$ to release the drug. In comparison with other formulations, F-4 shows a better drug release of $99.13 \%$ at the end of 10 $\min$. 


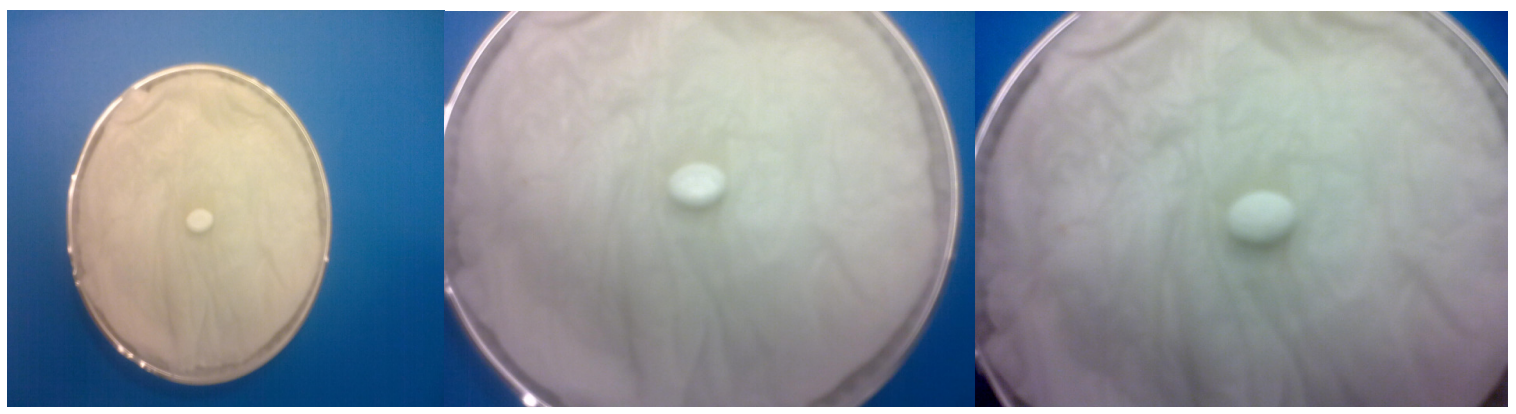

Figure 1: Wetting of mouth dissolving tablet of Loratadine (F-4) at 05,25 and 38 second respectively

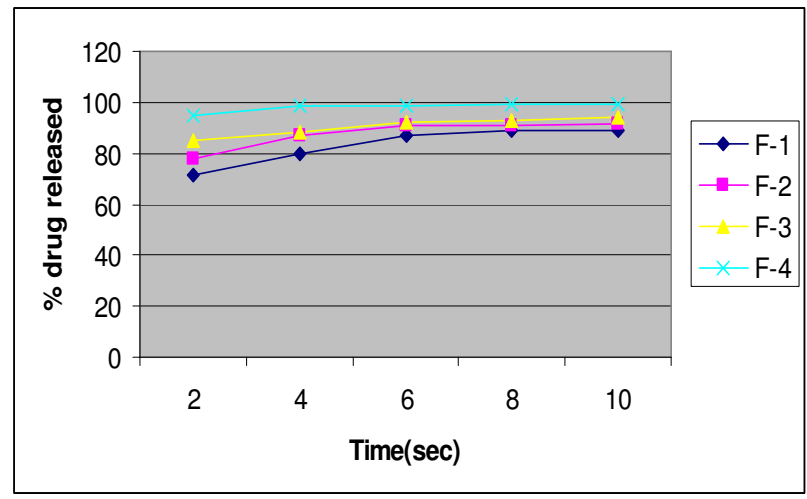

Figure 2: In vitro dissolution profile of mouth dissolving tablet of loratadine (F-4)

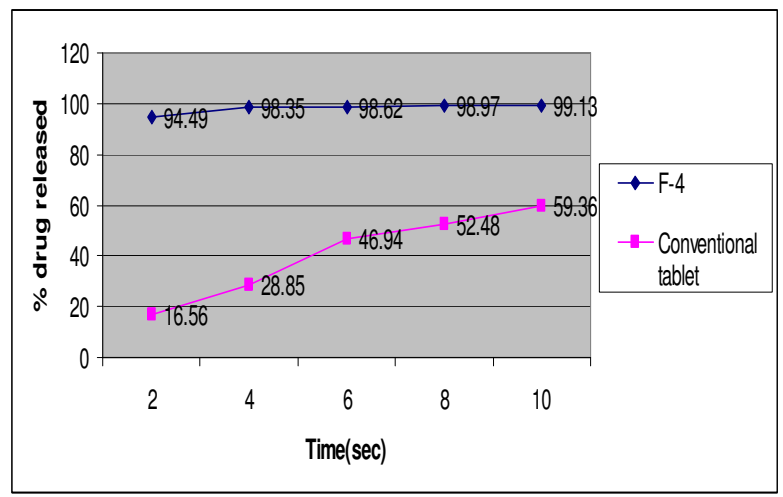

Figure 3: Comparis on of dissolution profile of $\mathrm{F}-4$ and the conventional tablet

Further the F-4 was compared with marketed conventional formulation (Loratin tablet, Square Pharmaceuticals Ltd) and found to be superior in terms of dissolution profile. F-4 formulation was selected for accelerated stability study. F-4 formulation was placed at $40^{\circ} \mathrm{C} / 75 \% \mathrm{RH}$ for 60 days. At 30 and 60 days, the tablets were examined for physical parameters and $I n$ vitro release studies as per $\mathrm{ICH}$ guidelines $\mathrm{Q} 1 \mathrm{C}^{11}$. There were no significant changes found when the values are compared with 0 day of formulation.

\section{CONCLUSION}

The release of drug from the F-4 formulation was quick when compared to F-2 and F-3 formulation. It shows that the combined effect of crosscarmellose sodium and pharmaburst B2 gives synergistic effect. Undoubtedly the availability of various technologies and the manifold advantages of MDT will surely enhance the patient compliance, low dosing, rapid onset of action, increased bioavailability, low side effect, good stability and its popularity in near future.

\section{ACKNOWLEDGEMENT}

The authors are grateful to Square Pharmaceuticals Ltd for providing gift sample of loratadine and Pharmaburst B2 and necessary facilities to carry out the research work.

\section{REFERENCES}

Charles R. Craig and Robert E. Stitzel(1997). Modern pharmacology with clinical applications. Little, Brown and company, New York. 5th edition, pp. 514.

David E, Armen H. T, Ethrin J Aand April W. Armstrong. (2008) Principles of pharmacology.The pathophysiologic basis of drug therapy. Wolters Kluwer (India) Pvt. Ltd, New Delhi, 2nd edition, pp. 815. 
Haria $\mathrm{M}$, et al. Loratadine: a reappraisal of its pharmacological properties and therapeutic use in allergic disorders. Drugs 1994; 48: 617-37.

Herbert A. Liberman, Leon Lachman and Joseph B. Schwartz. Pharmaceutical dosage forms(2005): Tablets volume-2, Marcel dekker, New York, $2^{\text {nd }}$ edition, pp. 165-167.

http://www.ich.org/cache/compo/363-271-1.html

Kanig, Joseph L.; Lachman, Leon; Lieberman, Herbert A. (1986). The Theory and Practice of Industrial Pharmacy (3 ed.). Philadelphia: Lea \& Febiger. ISBN 0-8121-0977-5.

Lene Noehr-Jensen, Per Damkier, Tanja Busk Bidstrup, Rasmus Steen Pedersen, Flemming Nielsen and Kim Brosen(2006). The relative bioavailability of loratadine administered as a chewing gum formulation in healthy volunteers. Eur J Clin Pharmacol 62: 437-445.

ME, Wells TI. (1998) Pharmaceutics: The Science of Dosage Form Design. 2nd Ed. pp 397. Churchill Livingstone, London, England.

Mukesh P. Ratnaparkhi, Mohanta G.P and Lokesh Upadhyay(2009). Review on: Fast dissolving tablet. Journal of pharmacy research, 2(1); 5-12.

Patrick J. Sinko(2006). Martin's Physical pharmacy and pharmaceutical sciences. Lippincott Williams and Wilkins, New York, 5th edition, pp, 557.

Rudnic E. and Schwartz J. B(1990). Oral solid dosage forms In: Remington's Pharmaceutical Sciences. 18 th ed. Ed. Gennaro, A. R. Mack Publishing Company. Easton, Pennsylvania, USA. pp. 1633-1665.

Suresh Bandari, Rajendar Kumar Mittapalli, Ramesh Gannu and Yamsani Madhusudan. Rao(2008). Orodispersible tablets: An overview, Asian journal of pharmaceutics, 2-11.

Swamy P.V, Shahidulla S.M, Shirsand S.B, Hiremath S.N and Md. Younus Ali(2008). Orodispersible tablets of carbamazepine prepared by direct compression method using 32 full factorial designs. Dhaka Univ. J. Pharm. Sci. 7(1): 1-5.

Tripathi(2000). Essential of medical pharmacology. Jaypee brothers, New Delhi. 4th edition, pp. 633.

United S tates of Pharmacopeia-National Formulary. USP 30 - NF 25.(2007) The Unit States Pharmacopeial Convention, Rockville, MD, Volume 1, pp. 644, 242, 645, 731 and 634. 